\title{
Expert System for Diagnosing Diseases Tubercolosis Using Bayes Method In Puskesmas Petumbukan
}

\author{
Muhammad Ridho Syahwana ${ }^{1}$, R. Mahdalena Simanjorang ${ }^{2}$ \\ ${ }^{1,2}$ Informatics Engineering Study Program, STMIK Pelita Nusantara, J1. St. Iskandar Muda \\ No. 1 Medan, Nort Sumatera, Indonesia, 20154 \\ E-mail:syahridho2@gmail.com
}

\begin{abstract}
Tuberculosis is an infection caused by acid-fast bacilli (AFB). Tuberculosis is an infectious disease apat affect anyone over the air. Tuberculosis is an infectious disease berbahaya.Tuberculosis a chronic or chronic disease that can strike between the age of 15-35 years. How to diagnose tuberculosis is by way of the expert of experts interviewed then test sputum samples using a lab to determine the positive or negative tuberculosis disease so it takes a long time. Therefore it takes an expert system with Bayesian methods to facilitate the penykit diagnosing tuberculosis. This expert system developed using Microsoft Visual Studio 2010 as well as by using Microsoft Access 2010 database.
\end{abstract}

Keywords : Diagnosis of tuberculosis, expert systems, Bayesian method, Microsoft Visual Studio 2010, Microsoft Accses 2010.

\section{Introduction}

The development of science and technology has progressed so rapidly. One is the increasing advances in technology to be used in the medical world. The need for a computer in the medical world that is as a supporting performance in order to speed up diagnosis of the disease in a swift, responsive, and accurate. Diagnosis of the disease in the medical world can sometimes take a long time, especially of rare diseases in the know by masyarakat.Ada steps to diagnose a disease such as interviewing patients about symptoms complained of the test samples in the laboratory to determine the diagnosis of the disease, but it is not effective and require considerable time to determine the results of laboratory samples. Examples of such cases occur when handling the diagnosing of the diseaseTuberculosis (TB) which takes a long time to obtain results. Researchers using an expert system to facilitate later in diagnosing tuberculosis disease by entering some data like the signs of symptoms of the disease to the herd data by research the expert in helping Tubercolosis.Untuk disease progressed Expert System applications, researchers are also using Bayes Method. Bayes method is used because it can calculate the probabilities on all hypotheses, so that if the value of the probability of high value then it will know how many percent positivity rate of tuberculosis disease patients.

\section{Theory}

\subsection{Expert system}

According to Professor Edward Feigenbaum in Muhammad Arhami (2004: 2) Expert System dalah an intelligent computer program that uses knowledge (Knowledge) and inference procedures to solve the problem is quite difficult so it takes an expert to complete.

\subsection{MetodeBayes}

Bayesadalah method is one method to overcome the uncertainty of the data. In this method, the use of the conditional probability is as the base, where the statistical science of probability of $\mathrm{X}$ in $\mathrm{Y}$ is the probability inteseksi $\mathrm{X}$ and $\mathrm{Y}$ of probailitas $\mathrm{Y}$.

Where:

$$
P H E=\frac{P E H \cdot P H}{P E}
$$

$\mathrm{P}(\mathrm{H} \mid \mathrm{E})$ : the probability of the hypothesis $\mathrm{H}$ if given evidence $\mathrm{E}$

$\mathrm{P}(\mathrm{E} \mid \mathrm{H})$ : probability evidence $\mathrm{E}$ if known hypothesis $\mathrm{H}$ 
$\mathrm{P}(\mathrm{H})$ : the probability of the hypothesis $\mathrm{H}$ regardless evidence any

$\mathrm{P}(\mathrm{E})$ : probability evidence $\mathrm{E}$

\subsection{Tuberculosis (TB)}

According to Shinta Sunaryati Septi (2011: 81) tuberculosis is an infection which is caused by acid-fast bacilli (AFB). Tuberculosis is an infectious disease apat affect anyone over the air. The main organ in attacking this disease are the lungs, or often known as pulmonary tuberculosis, there remains a wide variety of more diseases like tuberculosis that TB skin, glands TB, and TB Brain

\section{Research methods}

The method in this study was developed through a framework terleboh first. The description of the framework in the methods of this study are as follows:

\subsection{Identification of problems}

Identify problems in the study as less efesiennya to diagnose tuberculosis for a long time, the lack of computerization in the data store.

\section{2 analyze Problems}

Analysis of the problem that is studying the issues that will be discussed in the study by obtaining data that will be used. In this research is the problem that caused the duration of a process results in the diagnosis of tuberculosis, so it must need a system to speed up the handling in diagnosing tuberculosis disease.

\section{3 formulating Problems}

At this stage of formulation of the problem that will be created is to create a system to facilitate an pendiagnosannya. The expert system is a system that is in use in this study.

\subsection{Implementation of Algorithms Theorem Bayes To Diagnose Disease Tubercolosis}

The application of the algorithm method Bayes selected for diagnosing tuberculosis because it can menghintung probability that arise from the patient complained of symptoms, so they will find a positive or negative outcome of patients affected by tuberculosis.

\subsection{Data analysis}

The data analysis is an attempt to process data into information so that the characteristics of the data can be understood and useful for the solution of problems, particularly issues related to research. Another definition of the data analysis is an activity undertaken to change the data results of research into information that can later be used to draw conclusions.

The results of research that has been done, the data obtained tuberculosis diseases as follows:

1. Pulmonary TB

2. TB glands

3. TB Skin

4. Bone TB

5. TB Brain

Table 1

List of tuberculosis disease

\begin{tabular}{llll}
\hline Code & Disease & Information & Weight \\
\hline P1 & Pulmonary TB & $\begin{array}{l}\text { Tuberculosis disease that attacks and infected at the lung } \\
\text { Tuberculosis disease that attacks on the skin, usually as a chronic sore that never } \\
\text { Pealed. }\end{array}$ & 0.3 \\
Th & TB Skin & $\begin{array}{l}\text { Tuberculosis disease that attacks on the lymph, usually occurring enlarged lymph } \\
\text { nodes in the neck. }\end{array}$ & 0.5 \\
P3 & TB glands & $\begin{array}{l}\text { The tuberculosis disease attack on the spine in the thoracic area (back of the chest). } \\
\text { tuberculosis This usually affects children with an attack on the lining of the brain or } \\
\text { in commonly called meningitis. }\end{array}$ & 0.5 \\
P4 & Bone TB & TB Brain & 0.4 \\
P5 & &
\end{tabular}

Table 2

List of Symptoms Tubercolosis

\begin{tabular}{llc}
\hline CODE & SYMPTOMS & WEIGHT \\
\hline G01 & Persistent cough with sputum for three weeks or more. & 0.5 \\
G02 & Sputum mixed with blood & 0.7 \\
\hline
\end{tabular}




\begin{tabular}{|c|c|c|}
\hline CODE & SYMPTOMS & WEIGHT \\
\hline G03 & Shortness of breath and pain in the chest & 0.4 \\
\hline G04 & Weakness, loss of appetite, and weight loss also decreased & 0.6 \\
\hline G05 & Sweat at night even without activity & 0.2 \\
\hline G06 & Fever fever (mild fever) more than a month & 0.6 \\
\hline G07 & The emergence of a lump in the neck area, armpits, and groin & 0.6 \\
\hline G08 & Repeated diarrhea that does not heal with ordinary diarrhea drug & 0.2 \\
\hline G09 & $\begin{array}{l}\text { In case of partial bronchial obstruction (channel into the lungs) due to compression of the } \\
\text { enlarged lymph nodes will cause wheezing sound (the sound of breathing weakened) } \\
\text { accompanied by shortness }\end{array}$ & 0.4 \\
\hline G10 & $\begin{array}{l}\text { If there is fluid in the pleural cavity (wrapping lungs), can be accompanied by complaints of } \\
\text { chest pain. }\end{array}$ & 0.4 \\
\hline G11 & $\begin{array}{l}\text { When the bone, there will be symptoms such as bone infection at some point be able to form a } \\
\text { channel and lead to the overlying skin, in this estuary will discharge pus. }\end{array}$ & 0.8 \\
\hline G12 & $\begin{array}{l}\text { In children can about the brain (brain wrapper layer) and is referred to as meningitis } \\
\text { (inflammation of the lining of the brain), the symptoms are high fever, the loss of consciousness } \\
\text { and convulsions seizures }\end{array}$ & 0.8 \\
\hline G13 & Their scrophuloderma or TB skin (such as chronic ulceration and never healed). & 0.8 \\
\hline G14 & Phlycternular their conjungtivitis (sometimes in the eyes there is red, then there are white spots) & 0.2 \\
\hline G15 & The existence of specific lymphadenopathy (enlarged lymph nodes in the neck) & 0.8 \\
\hline G16 & In tuberculosis, enlarged glands normally would in a row or more than one & 0.4 \\
\hline
\end{tabular}

\subsection{Analysis Bayes Method}

Calculation of Bayesian methods in diagnosing tuberculosis diseasethe system is designed based on Bayes algorithm discussed in the calculation according to the symptoms suffered by a person. Persamaaa formula Bayes method is as follows:

$$
\begin{aligned}
& \mathrm{PHE}=\frac{P E H . P H}{P E} \ldots \ldots \ldots \ldots . . . . \\
& \mathrm{PHiE}=\frac{P E H i P H i}{n_{k=1} P E i P(H i)} . \\
& \mathrm{PHE}, \mathrm{e}=P H E \frac{P e E, H}{P e E} .
\end{aligned}
$$

Table 3

Table Value Bayes

\begin{tabular}{ll}
\hline Bayes theorem & $\begin{array}{l}\text { Value Probability } \\
\text { Bayes }\end{array}$ \\
\hline There is no & $0-0.2$ \\
Maybe & $0.3-0.4$ \\
Most likely & $0.5-0.6$ \\
definitely Hampi & $0.7-0.8$ \\
Certainly & $0.9-1.0$ \\
\hline
\end{tabular}

\subsection{Diagnose Disease Expert System Rule Tubercolosis}

rule 1: IFPersistent cough with sputum for three weeks or more is True

ANDSputum mixed with blood is True

ANDShortness of breath and pain in the chestis True

$A N D$ Weakness, loss of appetite, and weight loss also decreased is True

ANDSweat at night even without activityis True

$A N D F e v e r$ fever (mild fever) more than a month is True

$A N D T h e$ emergence of a lump in the neck area, armpits, and groin 
is True

$A N D$ In case of partial bronchial obstruction (channel into the lungs) due to compression of the enlarged lymph nodes will cause wheezing sound (the sound of breathing weakened) accompanied by shortness is True

$A N D$ If there is fluid in the pleural cavity (wrapping lungs), can be accompanied by complaints of chest pain is True

THENPulmonary TB

rule 2: IFFever fever (mild fever) more than a month's chestis True

$A N D T h e i r$ scrophuloderma or TB skin (such as chronic ulceration and never healed) is True

THENTB Skin

rule 3: IFPersistent cough with sputum for three weeks or more is True

$A N D F e v e r$ fever (mild fever) more than a month is True

ANDThe emergence of a lump in the neck area, armpits, and groin is True

$A N D$ In case of partial bronchial obstruction (channel into the lungs) due to compression of the enlarged lymph nodes will cause wheezing sound (the sound of breathing weakened) accompanied by shortness is True

$A N D$ The existence of specific lymphadenopathy (enlarged lymph nodes in the neck) is True

$A N D I n$ tuberculosis, enlarged glands normally would in a row or more than one is True

THENTB glands

rule 4: IFFever fever (mild fever) more than a monthis True

$A N D$ When the bone, there will be symptoms such as bone infection at some point be able to form a channel and lead to the overlying skin, in this estuary will discharge pus.is True

THENBone TB

rule 5: IFFever fever (mild fever) more than a month is True

ANDIn children can about the brain (brain wrapper layer) and is referred to as meningitis

(inflammation of the lining of the brain), the symptoms are high fever, the loss of consciousness and convulsions seizures is True

AND Repeated diarrhea that does not heal with ordinary diarrhea drug is True

THENTB Brain

\subsection{Case study}

Analysis of tuberculosis disease diagnosis with Bayesian methods can be loaded as in the following cases:

A case of tuberculosis disease, in which symptoms of the disease and answer as follows:

1. Sputum mixed with blood $=0.7=\mathrm{P}(\mathrm{E} \mid \mathrm{H} 1)$

2. Persistent cough with sputum for three weeks or more $=0.5=\mathrm{P}(\mathrm{E} \mid \mathrm{H} 2)$

3. Shortness of breath and pain in the chest $=0.4=\mathrm{P}(\mathrm{E} \mid \mathrm{H} 5)$

4. Fever fever (mild fever) more than a month $=0.6=\mathrm{P}(\mathrm{E} \mid \mathrm{H} 6)$

Calculation Method Using Bayes

a) Determining the value of Probability

Define in advance the value of the probability of any evidence for each hypothesis based on the available sample data using Bayes probability formula.

$$
\begin{aligned}
& \mathrm{G} 02=\mathrm{P}(\mathrm{E} \bigotimes \mathrm{H} 1)=0.7 \\
& \mathrm{G} 01=\mathrm{P}(\mathrm{E} \otimes \mathrm{H} 2)=0.5 \\
& \mathrm{G} 03=\mathrm{P}(\mathrm{E} \otimes \mathrm{H} 5)=0.4 \\
& \mathrm{G} 06=\mathrm{P}(\mathrm{E} \otimes \mathrm{H} 6)=0.6
\end{aligned}
$$

b) Determining the value of the Universe

$n$

Looking universe by summing the values of the hypothesis

$$
G 1+\otimes+G n
$$

Gn 


$$
\begin{array}{rl}
\mathrm{G} 02 & =\mathrm{P}(\mathrm{E} \bigotimes \mathrm{H} 1)=0.7 \\
\mathrm{G} 01 & =\mathrm{P}(\mathrm{E} \otimes \mathrm{H} 2)=0.6 \\
\mathrm{G} 03 & =\mathrm{P}(\mathrm{E} \otimes \mathrm{H} 5)=0.4 \\
\mathrm{G} 06 & =\mathrm{P}(\mathrm{E} \otimes \mathrm{H} 6)=0.6 \\
n & 0.7+0.5+0.4+0.6=2.2
\end{array}
$$

Once the sum is known, then obtained the formula for calculating the value of the universe:

$P H i=\frac{P H i}{n_{G n}^{n}}$

$\mathrm{G} 02=\mathrm{P}(\mathrm{H} 1)=\frac{0.7}{2.2}=0.31$

$\mathrm{G} 01=\mathrm{P}(\mathrm{H} 2)=\frac{0.5}{2.2}=0.22$

$\mathrm{G} 03=\mathrm{P}(\mathrm{H} 5)=\frac{0.4}{2.2}=0.18$

$\mathrm{G} 06=\mathrm{P}(\mathrm{H} 6)=\frac{0.6}{2.2}=0.27$

c) Determining the value of probability $\mathrm{P}$ (Hi)

Once the value of $\mathrm{P}(\mathrm{Hi})$ is known, the value of the probability of the hypothesis $\mathrm{H}$ regardless of any evidence.

$$
0.31 \otimes 0.7+0.22 \otimes 0.5+0.18 \otimes 0.4+0.27 \otimes 0.6=0.561
$$

Gn

d) Determining the value of $\mathrm{P}(\mathrm{Hi} \mid \mathrm{E})$

Finding the value of $\mathrm{P}(\mathrm{Hi} \otimes \mathrm{E})$ or the probability of the hypothesis $\mathrm{Hi}$ is true if given evidence $\mathrm{E}$.

$P H i=\frac{P H i \otimes P(E \mid H i)}{n}$

$\mathrm{P}(\mathrm{H} 1 \mid \mathrm{E})=\frac{\underset{0.31 \llbracket 0.7}{G n}}{0.561}=0.38$

$\mathrm{P}(\mathrm{H} 2 \mid \mathrm{E})=\frac{0.22 \bowtie 0.5}{0.561}=0.19$

$\mathrm{P}(\mathrm{H} 5 \mid \mathrm{E})=\frac{0.18 \bowtie 0.4}{0.561}=0.12$

$\mathrm{P}(\mathrm{H} 6 \mid \mathrm{E})=\frac{0.27 区 0.6}{0.561}=0.28$

e) Determining the value of Bayes

After all values $P(H i \otimes E)$ is known, then the total the entire value Bayes with the following formula:

n

$$
=P(E \mid H 1) \otimes P(H 1 \mid E 1)+\ldots+P(E \mid H i) \otimes P(H i \mid E i)
$$

a. Pulmonary tuberculosis disease

$$
\begin{aligned}
& n \\
& \quad=0.7 \otimes 0.38+0.5 \otimes 0.19+0.4 \otimes 0.12+0.6 \otimes 0.28 \\
& =0.64 * 100 \% \\
& =64 \%
\end{aligned}
$$

b. Skin tuberculosis disease

$n$

$$
=0.6 \otimes 0.28
$$

Gn

$=0.168 \otimes 100 \%$

$=16.8 \%$

c. Gland tuberculosis disease 
$n$

$=0.6 \otimes 0.28$

Gn

$=0.168 \otimes 100 \%$

$=16.8 \%$

d. Bone tuberculosis disease

$n$

$=0.6 \bigotimes 0.28$

Gn

$=0.168 \otimes 100 \%$

$=16.8 \%$

e. Brain tuberculosis disease

$n$

$=0.6 \otimes 0.28$

Gn

$=0.138 \otimes 100 \%$

$=16.8 \%$

Of the calculation process using Bayesian methods above, it can be seen that the patient "Great Possibilities" underwent pulmonary tuberculosis disease-paru with value of 0.64 or $64 \%$ confidence.

\section{Results and Discussion}

\subsection{Use Case Diagram}

Use case diagramsdigunakanuntukmenggambarkandanmenganalisisinteraksi the user terjadiantara dansystemsehinggadapatdipahamidenganlebihmudah. Here is a use case diagram tuberculosis disease diagnosis expert system using Bayesian methods.

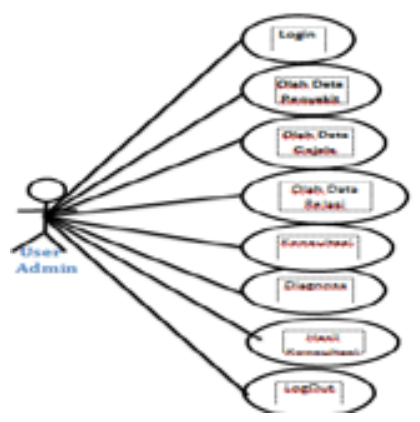

Picture 1. Use Case Diagam Diagnosis of tuberculosis disease

Explanation Use Case Diagram:

1) Users must login first to get into the system.

2) The user then perform data processing both the data relationships, symptom data, and data of diseases.

3) Users can also enter data consultation as symptoms in the patient's natural to eventually get the results of the consultation.

Implementation is the execution and at the same time for sistemyang testing has been approved and Bayes Method which is used as a draft in an expert system. 
Journal of Computer Networks, Architecture and High Performance Computing e-ISSN 2655-9102, Volume 2, No. 1, January 2020, pp 7-14

\subsection{Form symptom}

\begin{tabular}{|c|c|c|c|c|c|}
\hline \multicolumn{6}{|c|}{ Data Gojala } \\
\hline & $m$ & tana & a & $m$ & ini \\
\hline \multicolumn{2}{|r|}{$\operatorname{son} x \sin 1$} & \multicolumn{4}{|l|}{ wisesen } \\
\hline \multirow[t]{15}{*}{, } & E & \multicolumn{4}{|c|}{ 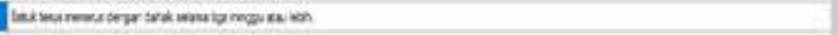 } \\
\hline & 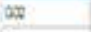 & \multicolumn{4}{|c|}{ Sinberoution } \\
\hline & on & \multicolumn{4}{|c|}{ 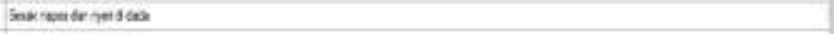 } \\
\hline & OD. & \multicolumn{4}{|c|}{ 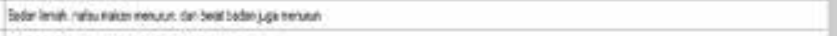 } \\
\hline & $3 \%$ & \multicolumn{4}{|c|}{ 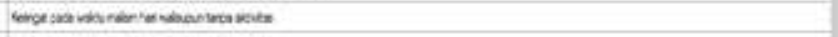 } \\
\hline & ox & \multicolumn{4}{|c|}{ 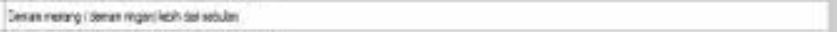 } \\
\hline & ast & \multicolumn{4}{|c|}{ 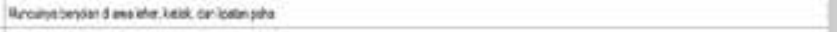 } \\
\hline & $a x$ & \multicolumn{4}{|c|}{ 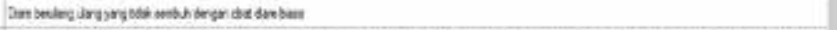 } \\
\hline & ass & \multicolumn{4}{|c|}{ 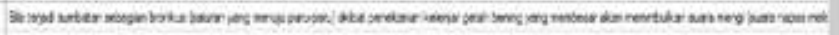 } \\
\hline & gth & \multicolumn{4}{|c|}{ 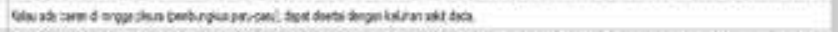 } \\
\hline & at & \multicolumn{4}{|c|}{ 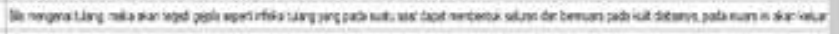 } \\
\hline & ot & \multicolumn{4}{|c|}{ 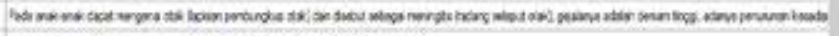 } \\
\hline & at & \multicolumn{4}{|c|}{ 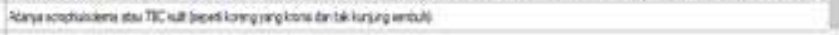 } \\
\hline & ok & \multicolumn{4}{|c|}{ 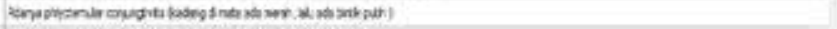 } \\
\hline & ats & \multicolumn{4}{|c|}{ 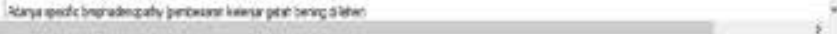 } \\
\hline
\end{tabular}

Figure 2. Interface Form Symptoms

\subsection{Form Consultation}

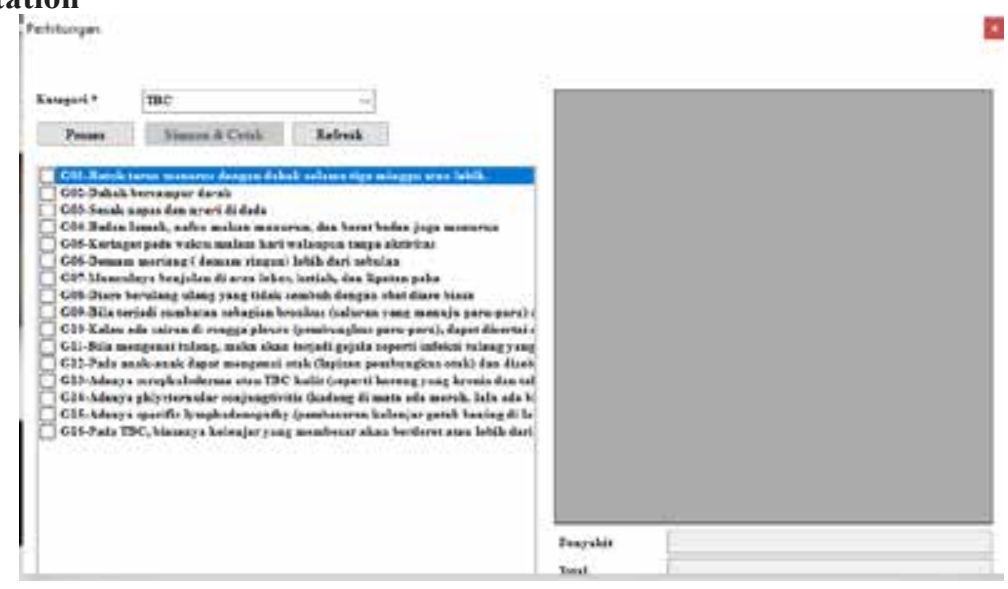

Figure 3. Interface Consultation Form

\subsection{Form reports Results}

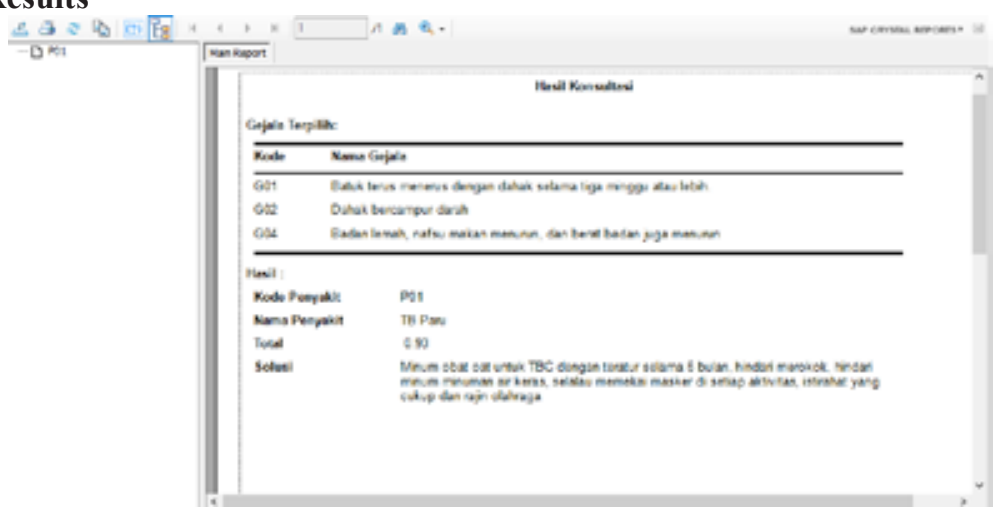

Figure 4. Interface Form Reports 


\section{Conclusion}

Based on the research and discussion above, it can be concluded as follows:

1) Can be analyzed in diagnosing tuberculosis.

2) Can design a system for diagnosing tuberculosis expert menggunakanSistem with Bayes Method into Micrososft Access database.

3) Program can apply expert system to diagnose tuberculosis using Bayes methods.

\section{Reference}

[1]. Erick Kurniawan, 2010. Visual Basic 2010. Yogkarta: Andi

[2]. Double Anggara, Gede Pramayu, Arif Wicaksana. Build Expert System Using Bayes Theorem To Diagnose Lung Disease. National Seminar on Information and Multimedia Technology, 2016, 81.

[3]. Haer Talib, 2011. The Complete Guide to Microsoft Access 2010. Jakarta: PT Gramedia.

[4]. Hengki Tamando Sihotang. Perancanagan Expert Systems Applications. TIKomSIN, 2018, 6 (1), 37.

[5]. Muhammad Arhami, 2004. Basic Concepts of Expert Systems. Yogyakarta: Andi.

[6]. Johan Wahyudi Muhammad, Abdul Fadl. SistemPakar For Identifying Disease Udang Galah Methods Bayes Theorem, Srjana Journal of Information Engineering, 2013, 1 (1), 15.

[7]. Nur Aini, Ramadiani, Heliza Rahmania Hatta. Expert System Pendiagnosa tuberculosis disease. Mulawarman Informatics Journal, 2017, 12 (1), 57.

[8]. Septi Shinta Sunaryati, 2011. 14 Most Frequently Diseases Attacking and Very Mematikan. Yogyakarta: Flash Books.

[9]. Windah Supartini, Hindarto. Web-Based Expert System Forward Chaining Method In Early Disease Diagnosing tuberculosis in East Java. KINETIC, 2016, 1 (3), 149.

[10]. Yossi Octavina, Abdul Fadlil. Expert System to Diagnose Respiratory Disease and Lung On Method Using Certainty Factor. Bachelor of Engineering Informatics Journal, 2016, 2 (2), 1126. 